\title{
Physicochemical Characterization and Electrocatalytic Evaluation of Dendritic Core-shell Au@Pd/C Electrocatalysts for the Oxygen Reduction Reaction
}

\author{
E. Y. Cervantes-Aspeitia ${ }^{1,2}$, M. L. Hernández-Pichardo ${ }^{1, *}$, R. G. González-Huerta ${ }^{2}$, P. Del Angel ${ }^{3, *}$, \\ M. Tufiño-Velázquez ${ }^{4}$ \\ ${ }^{1}$ Instituto Politécnico Nacional-ESIQIE, Laboratorio de Nanomateriales Sustentables, UPALM, \\ México City, 07738, México. \\ ${ }^{2}$ Instituto Politécnico Nacional-ESIQIE, Laboratorio de Electroquímica, UPALM, México City, \\ 07738, México. \\ ${ }^{3}$ Instituto Mexicano del Petróleo, Caracterización de Materiales Naturales y Sintéticos, México City, \\ 07730, México. \\ ${ }^{4}$ Instituto Politécnico Nacional-ESFM, Laboratorio de Física Avanzada, UPALM, México City, \\ 07738, México. \\ *E-mail: pangel@imp.mx, mhernandezp@ipn.mx
}

doi: $10.20964 / 2020.09 .86$

Received: 6 June 2020 / Accepted: 21 xJuly2020 / Published: 10 August 2020

\begin{abstract}
Dendritic core-shell Au@Pd nanoparticles supported on carbon (D-Au@Pd/C) were synthesized by the seed-growth method. Pd dendrite formation on the Au surface was attributed to the nucleation and epitaxial growth of Pd atoms on specific facets of the Au NPs in the presence of adsorbed CTAC. In contrast, anisotropic palladium growth occurred over the uncapped planes of the gold core. The composition, morphology, and particle size of these catalysts were analyzed by HRTEM, HAADFSTEM, EDS mapping, XRD, and XPS. The electrocatalytic performance of the as-prepared catalyst in the ORR was compared to that of a commercial Pd/C catalyst. The superior performance of the D$\mathrm{Au} @ \mathrm{Pd} / \mathrm{C}$ material was related to the porous Pd shell and the synergetic effects between both metals. The dendritic structure allowed for an increased number of exposed active sites, and the interplay between both metals favored the suppression of the adsorption of hydroxyl and super hydroxyl groups on the active sites, enhancing the ORR kinetics of the Pd shell in acidic media.
\end{abstract}

Keywords: Dendritic shape; Au@Pd Nanoparticles; Carbon, HAADF-STEM; Oxygen Reduction Reaction; Electrocatalysis.

\section{FULL TEXT}


(C) 2020 The Authors. Published by ESG (www.electrochemsci.org). This article is an open access article distributed under the terms and conditions of the Creative Commons Attribution license (http://creativecommons.org/licenses/by/4.0/). 